\title{
A meta-analysis of perventricular device closure of perimembranous ventricular septal defect
}

\author{
Zhi-Nuan Hong ${ }^{1 \dagger}$, Qiang Chen ${ }^{2 \dagger}$, Li-Qin Huang ${ }^{3}$ and Hua Cao ${ }^{1 *}$
}

\begin{abstract}
Background: To investigate the safety and efficacy of perventricular device closure of perimembranous VSD (pmVSD).

Methods: PubMed and Scopus were searched for studies in English focusing on perventricular device closure of pmVSD published up to the end of March 2019. We used a random-effects model to obtain pooled estimates of the success and complication rates.

Results: A total of 15 publications comprising 1368 patients with pmVSD were included. The median follow-up duration was 2 months to 5 years, with a mean patient age ranging from 2 months to 56 years. The pooled success rate was $0.95\left(I^{2}=86.2 \%, P=0.000\right)$. The pooled rate of postoperative residual shunting was 0.02 ( $95 \% \mathrm{Cl}: 0.01-0.03$, $\mathrm{I}^{2}=87.3 \%, P<0.001$ ). The pooled rate of residual shunting in the follow-up period was 0.001 ( $95 \% \mathrm{Cl}:-0.001-0.002$, $\left.I^{2}=30.5 \%, P=0.126\right)$. The pooled estimated rate of severe complications was $0.074\left(95 \% \mathrm{Cl}: 0.046-0.102, I^{2}=30.5 \%\right.$, $P=0.126)$. The pooled incidence of complete atrioventricular block (CAVB) was 0.002 (95\% Cl: $0.000-0.005, I^{2}=0.0 \%$, $P=0.577)$.

Conclusions: Perventricular device closure may be an alternative to conventional surgical repair in selected patients with pmVSD. The success rate was stable regarding the publication year and sample size and suggested both the short learning curve of this technology and its potential for wide application. The incidence of severe arrhythmia, especially CAVB, was low. These good results may be limited by the number of enrolled patients, and a more detailed and larger sample is required for further analysis.
\end{abstract}

Keywords: Perventricular device closure, Perimembranous ventricular septal defect, Meta-analysis

\section{Introduction}

Ventricular septal defect (VSD) is one of the most common congenital hearts defects (CHDs), accounting for $20 \%$ of all forms of congenital cardiac malformations, and $80 \%$ of VSD cases are perimembranous VSD $[1,2]$. Conventional surgical repair of VSD under cardiopulmonary bypass $(\mathrm{CPB})$ is the gold standard treatment [3]. However, this approach cannot avoid the potential for CPB-related complications or complete atrioventricular block (cAVB),

\footnotetext{
* Correspondence: caohua0791@163.com

${ }^{+}$Zhi-nuan Hong and Qiang Chen contributed equally to this study.

Zhi-nuan Hong and Qiang Chen share first authorship.

'Department of Cardiac Surgery, Fujian Provincial Maternity and Children's

Hospital, Affiliated Hospital of Fujian Medical University, Fuzhou 350001,

People's Republic of China

Full list of author information is available at the end of the article
}

the surgical incision scar or prolonged recovery [4-7]. With the improvement and development of various devices, transcatheter device closure of pmVSD has also gradually gained popularity in most medical centers with a promising closure success rate [8-10]. Based on the above two methods, perventricular device closure of pmVSD guided by transesophageal/transthoracic echocardiography (TEE/TTE) was developed and has been widely applied in China, with promising results. This study aimed to obtain pooled estimates of the success and morbidity rates after perventricular device closure of pmVSD based on a meta-analysis of the current literature. These clinical data could serve as important evidence for the acceptance of perventricular device closure of pmVSD as an alternative to conventional surgical repair of VSD. This analysis 
could also guide further research on and development of occluders to achieve better outcomes with fewer complications.

\section{Methods}

\section{Literature search strategy}

A search of the English literature from the start date of each database up to March 2019 was conducted by 2 independent researchers using PubMed (MEDLINE), EMBASE, and the Cochrane Central Register of Controlled Trials with the following search terms: ventricular septal defect, perimembranous, mini-invasive, transthoracic, intraoperative, perventricular, and device closure. From this search list, studies investigating the results of perventricular device closure of pmVSD were identified. Reference lists of the included articles were further examined to identify other relevant studies. Excluded studies and the reasons for their exclusion were listed and examined by a third researcher.

\section{Study selection and quality assessment}

The inclusion criteria included studies (randomized and nonrandomized studies) reporting perventricular device closure of congenital pmVSD in humans. The exclusion criteria included case series already included in multicenter studies, case reports with sample sizes less than 10, and reports of acquired pmVSD following myocardial infarction. Our search identified 165 articles, of which 150 were excluded (Fig. 1). A total of 15 articles [11-25] were included and further analyzed. Eight studies were case series, and the other 7 studies were case-control studies. Perventricular device closure was compared with surgical repair in 5 studies, the effectiveness between symmetrical and asymmetrical occluders was compared in 1 study, and guidance with TTE and TEE in regard to feasibility was compared in 1 study.

This meta-analysis included 8 case series and 7 casecontrol studies. We used the Newcastle-Ottawa Scale (NOS) to assess the quality of the case-control studies. The NOS assesses the quality of studies based on the

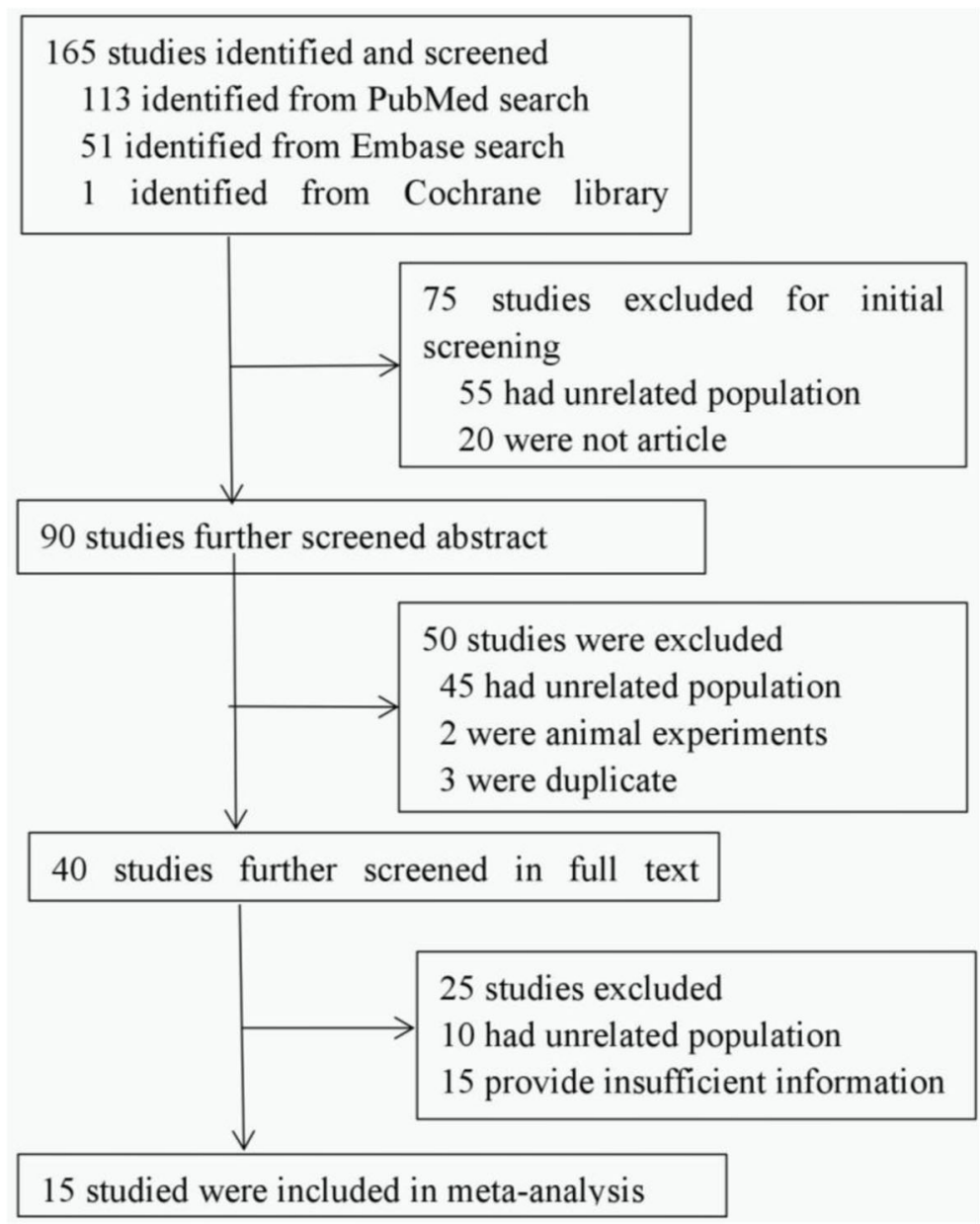

Fig. 1 Flow chart of literature selection 
selection of the cases and controls (0-4 stars), comparability of the cases and controls ( $0-2$ stars) and the ascertainment of exposure (0-4stars). NOS scores $>6$ stars are considered to indicate high quality [26].

We chose an 18-item, validated quality appraisal tool to evaluate the methodological quality of the case series. The quality assessments for each item were binary determinations of various aspects of the study, including the study objective, study population, intervention and cointervention, outcome measures, statistical analysis, results and conclusions, competing interests, and sources of support. High quality scores were $\geq 14$ [27]. Disagreements in the quality assessment were resolved through discussion.

\section{Data extraction}

Relevant data were extracted by two authors (Zhi-Nuan Hong and Li-Qin Huang) and entered into an electronic database. The data included publication details, including the publication year and first author, the device type, VSD size, sample size, age, success rate, complications rate, and median follow-up period. Successful device closure was defined as a residual shunt $<2 \mathrm{~mm}$ detected by TTE or TEE. Residual shunts, arrhythmias, and valvular lesions were considered permanent if they were reported and remained present at the time of the latest follow-up visit, regardless of severity. Residual shunts included all color jets observed across the VSD after deployment of the device. Complete atrioventricular block was further divided into transient or permanent. Valvular lesions included new-onset, device-related lesions with the exclusion of transient, early lesions that disappeared in the postdeployment period. Data regarding other significant complications, such as device embolization, hemolysis and thromboembolism, were also extracted.

\section{Statistical analysis}

Baseline characteristic data are presented as the median. Zero-event rates were approximated with $[1 /(4$ *sample size $)$ ] to allow calculation of the pooled occurrence rates. If a particular event was not reported in a study, then this study was excluded from the pooled analysis of these events.

We used a funnel plot of the sample size plotted against the operational success rate to evaluate the possibility of publication bias. The random-effects model was used to obtain the pooled estimates of the success rate and different types of complication rates. This study assumed that the total of 15 studies represented a random sample from the larger population of such studies. Each study had its own underlying effect size. The random-effects model assumed that there was a mean population effect size for which the study-specific effect varied. Thus, we could examine interstudy heterogeneity, such as differences in the study design type and definitions of success, as well as complications. We used the inconsistency statistic $\left(\mathrm{I}^{2}\right)$ to evaluate the extent of heterogeneity. An $\mathrm{I}^{2}$ value greater than $50 \%$ was considered to indicate substantial heterogeneity. A 2 -sided test at the $5 \%$ level was defined as indicating statistical significance, as determined using Stata version 15 (Stata Corp, College Station, TX, USA). Publication bias was tested using a funnel plot and Egger's test. We used a trim-and-fill method to provide the potential missing trials if publication bias was evident.

\section{Results \\ Publication bias}

A total of 15 studies (Table 1) investigated success and complication rates in 1368 patients and were included in the analysis. The median follow-up duration ranged from 2 months to 5 years, with the mean age of patients ranging from 2 months to 56 years. The sex rate was reported in 12 studies, including 1259 patients, 637 of whom were male. The pooled success rate was $0.95\left(\mathrm{I}^{2}=86.2 \%, P=0.000\right)$. Statistical evidence of publication bias was detected by a funnel plot (Fig. 2) and Egger's and Begg's test. The funnel plot showed funnel asymmetry, largely suggesting the presence of publication bias. P was 0.0092 in Begg's test, and P was 0.001 in Egger's test; both of these $P$ values are less than 0.05 and suggest publication bias. We further used the trim-and-fill method to evaluate the publication bias. No trimming or filling was performed, and the $95 \% \mathrm{CI}$ of the pooled operational success rate results was stable, which suggested an acceptable publication bias (Fig. 3).

\section{Outcomes}

The success rate of perventricular device closure of pmVSD was high, with 11 out of 15 studies reporting a success rate of greater than $90 \%$. Only 4 studies (sample size ranging from 12 to 61 ) reported a success rate less than $90 \%$. The Q statistic showed evidence of substantial heterogeneity $\left(\mathrm{I}^{2}=86.2 \%, P=0.000\right)$, and we chose the random-effects model. The pooled estimate of the overall success rate of device closure in the 15 studies was 0.95 (95\% CI: 0.92-0.97) (Fig. 4).

To explore the heterogeneity, we performed a subgroup analysis by study type and divided all studies into the case series and case-control groups (Fig. 5). The $\mathrm{I}^{2}$ was $44.3 \%$ in the case-control group and $71.4 \%$ in the case series group. Compared with $86.2 \%$, both groups showed a lower $\mathrm{I}^{2}$, and this result suggests that the study type may be a source of heterogeneity. Meta-regression analysis indicated no significant correlation between the success rate and the following factors: publication year, sample size, study type, mean age, mean VSD size, male prevalence and TTE/TEE guidance (all $P>0.05$ ). A sensitivity analysis results were further performed. Excluding 3 studies with a $100 \%$ success rate, the pooled success rate was 0.92 (95\% CI: $0.90-0.94, \mathrm{I}^{2}=31.1 \%, P=$ 
Table 1 Study characteristics

\begin{tabular}{|c|c|c|c|c|c|c|c|c|}
\hline NO. & First author & Year & Sample & Male & Study type & Quality score & $\begin{array}{l}\text { Hospital stay } \\
(x \pm s, d)\end{array}$ & $\begin{array}{l}\text { Follow-up } \\
\text { (median year) }\end{array}$ \\
\hline 1 & Changping Gan & 2008 & 30 & 16 & case series & 15 & $3.6 \pm 0.7$ & 0.50 \\
\hline 2 & Xiang-Jun Zeng & 2008 & 12 & 3 & case series & 15 & / & / \\
\hline 3 & Xing Quansheng & 2009 & 21 & 13 & case series & 16 & / & / \\
\hline 4 & Kaiyu Tao & 2010 & 61 & 34 & case series & 15 & $5.4 \pm 1.3$ & 1.00 \\
\hline 5 & Hua Cao & 2011 & 18 & / & case series & 15 & $3.5 \pm 1.3$ & 0.50 \\
\hline 6 & Da Zhu & 2012 & 40 & / & case series & 15 & / & 1.20 \\
\hline 7 & Qiang Chen & 2012 & 89 & 38 & case-control & 7 stars & $6.1 \pm 0.6$ & 1.50 \\
\hline 8 & Gui-Can Zhang & 2013 & 71 & 36 & case-control & 8 stars & / & 3.37 \\
\hline 9 & Lin Liu & 2013 & 47 & / & case series & 14 & $4.2 \pm 0.6$ & 1.86 \\
\hline 10 & Shunmin Wang & 2013 & 61 & 33 & case series & 15 & / & 2.81 \\
\hline 11 & Yu Kun Luo & 2014 & 173 & 101 & case-control & 7 stars & $9.3 \pm 4.7$ & / \\
\hline 12 & Yijie Hu & 2014 & 33 & 15 & case-control & 7 stars & $5.4 \pm 1.5$ & 1.67 \\
\hline 13 & Yong Sun & 2016 & 41 & 16 & case-control & 8 stars & $9.0 \pm 3.0$ & 2.30 \\
\hline 14 & WB Ou-yang & 2017 & 581 & 284 & case-control & 8 stars & / & 2.38 \\
\hline 15 & Guan-Hua Fang & 2018 & 90 & 4 & case-control & 8 stars & $4.2 \pm 1.6$ & 1.00 \\
\hline
\end{tabular}

0.142). The heterogeneity was lower after excluding studies with a $100 \%$ success rate, and no significant difference in the success rate was found.

The most common minor complication was residual shunting, documented in 95 subjects among the 15 studies with 1368 patients. The pooled rate of postoperative residual shunting was 0.02 (95\% CI: $0.01-0.03, \mathrm{I}^{2}=87.3 \%, P<0.001$ )
(Fig. 6) The pooled rate of follow-up residual shunting was 0.001 (95\% CI: - 0.001-0.002, $\mathrm{I}^{2}=30.5 \%, P=0.126$ ).

A total of 80 patients were converted to conventional surgical repair. The reasons for conversion to conventional surgical repair included significant residual shunting (36.4\%), mild to significant aortic regurgitation (35.2\%), severe arrhythmia (11.4\%), failure to establish a path $(9.1 \%)$,

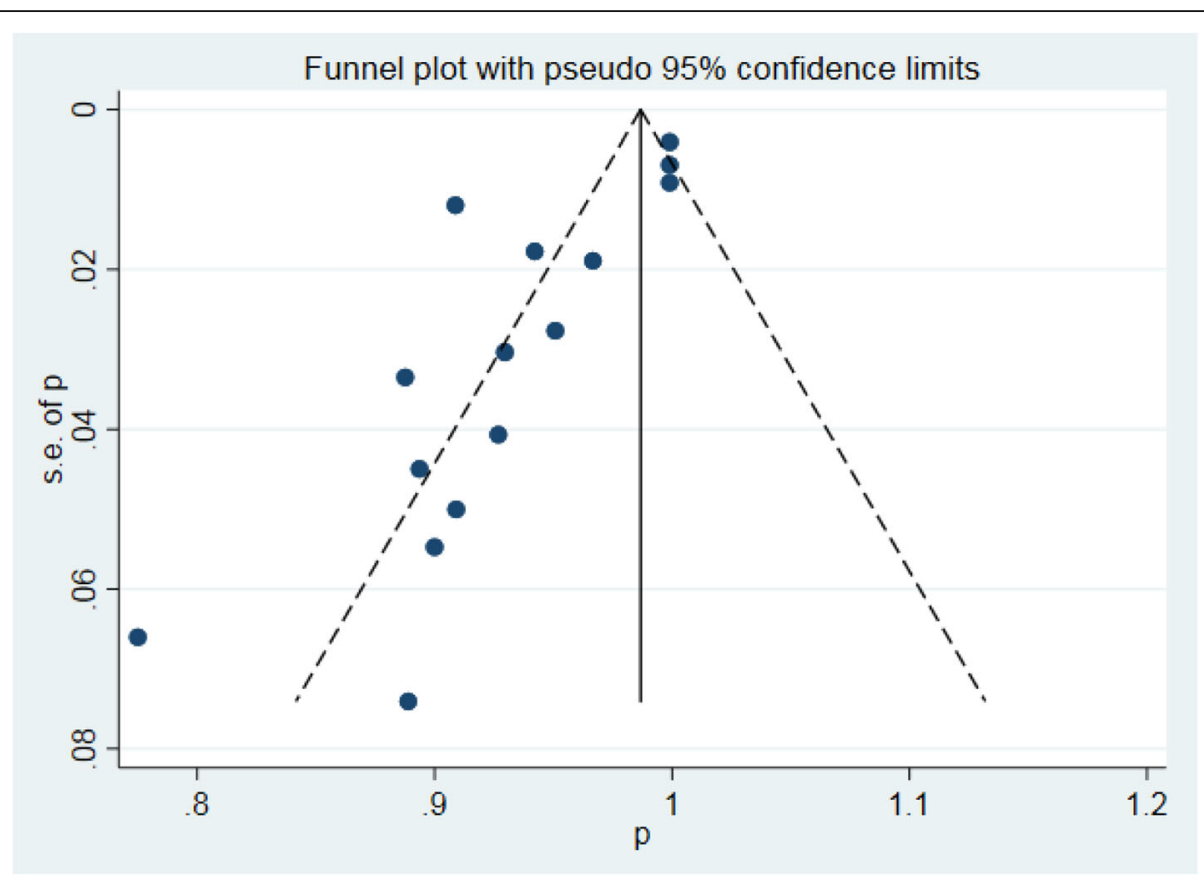

Fig. 2 Funnel plot based on the operational success rate 


\section{Filled funnel plot with pseudo $95 \%$ confidence limits}

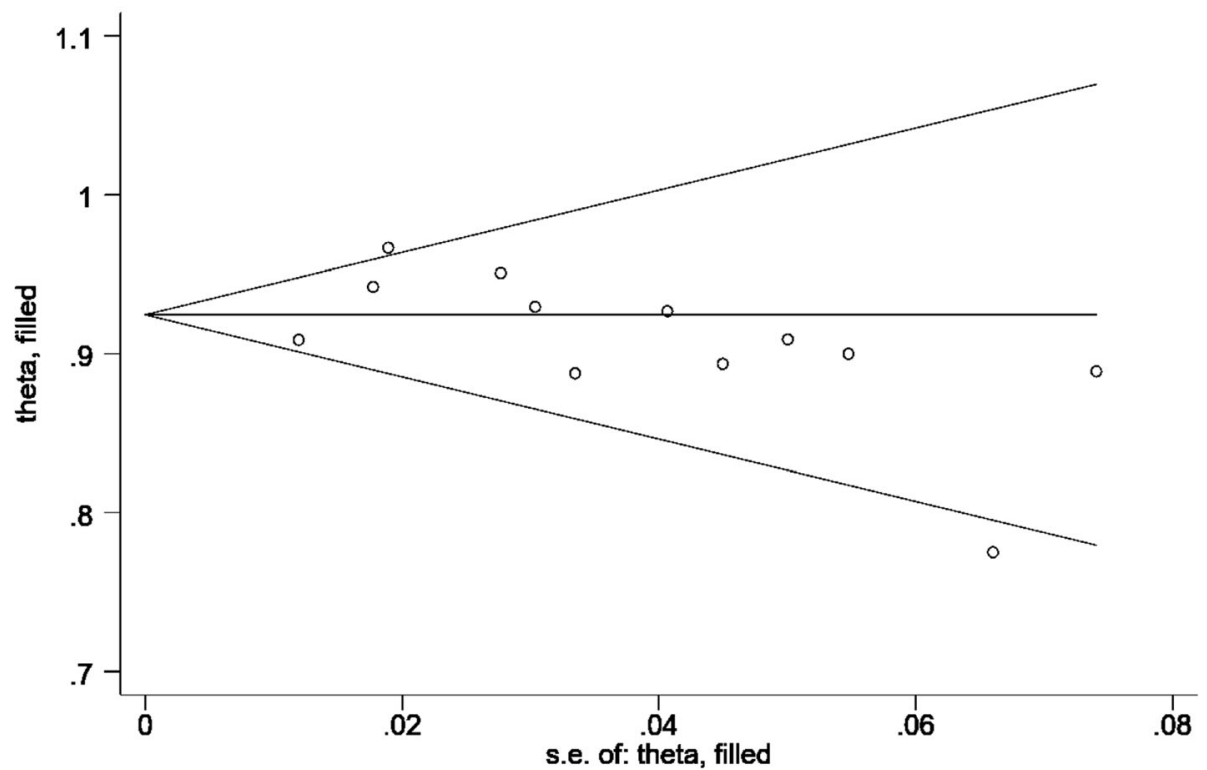

Fig. 3 Funnel plot using the trim-and-fill method based on the operational success rate

and mild to significant tricuspid regurgitation (8.0\%). Few patients required blood transfusion with a median rate of 0\% (95\% CI:-0.003-0.005, $\mathrm{I}^{2}=0, P=0.739$ ), representing $4 /$ 284 patients in 8 studies. The pooled rates of intraoperative, postoperative and follow-up severe complications are shown in Table 2.

\section{Discussion}

Perventricular device closure is a common treatment for VSD. The first real off-pump perventricular device closure of VSD was conducted in animal experiments in 1997 under TEE guidance and then applied in an infant with muscular VSD [28]. Subsequently, perventricular device

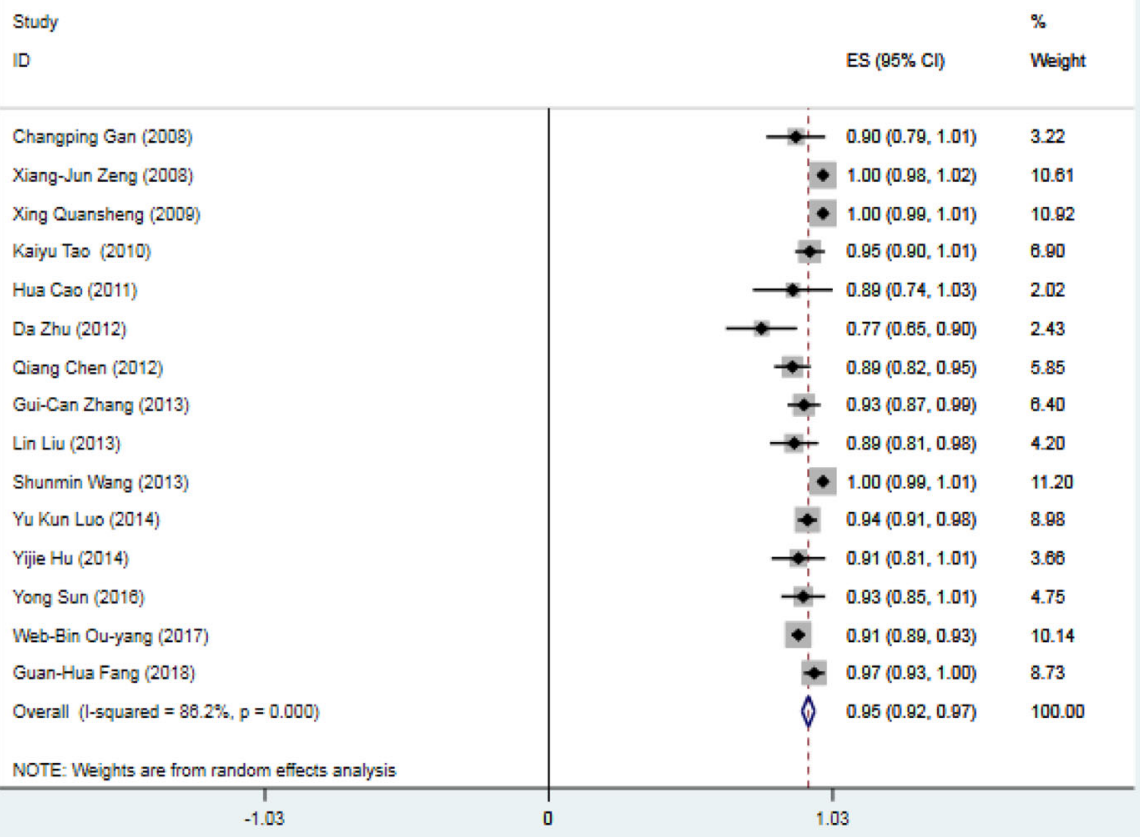

Fig. 4 Forest plot of operational success rate 




Fig. 5 Forest plot of operational success rate stratified by study type

closure of pmVSD was first reported in 2004 [29]. Recently, this technology has been widely applied in China. However, perventricular device closure of pmVSD is not applied worldwide due to safety concerns, especially concerns of heart block. Through this systematic review, we have attempted to evaluate the efficacy and safety of this technology.

The included studies were 8 case series and 7 casecontrol studies with a high quality and acceptable publication bias. The invasive intervention limited the blinding of the participants and personnel, and this contributed to the lack of RCTs. We contributed the bias to the following factors: first, the different study designs; second, the lack of multicenter studies in this analysis and the different patient selection criteria among the single centers; and third, the increased likelihood of studies with promising results being accepted and published.

We defined operational success as patients without fatal or severe early-term or late-term complications requiring reoperation. The pooled success rate of perventricular device closure was 0.95 (95\% CI: 0.92-0.97, $\left.\mathrm{I}^{2}=86.2 \%, P=0.000\right)$, including 15 studies with 1368 patients. The subgroup analysis suggested that the study type may be a source of heterogeneity. Furthermore, no uniform patient inclusion criteria were applied in all medical centers. However, only patients with isolated pmVSD were included, and patients with other coexisting cardiac anomalies, severe pulmonary hypertension, or significant aortic prolapse and newborns or young infants with a large VSD were excluded. The subaortic rim was required to be greater than $1-2 \mathrm{~mm}$. The VSD size ranged from 4 to $12 \mathrm{~mm}$. There was no correlation between the operational success rate and the following factors: publication year, sample size, study type, mean age, mean VSD size and TTE/TEE guidance, which indicates the short learning curve and easy promotion of this technology. Compared with conventional surgical repair, there is no need for cardiopulmonary bypass (CPB) in perventricular device closure. Compared with the transcatheter approach, the perventricular approach provides direct access and facilitates manipulation of the device position and orientation during device deployment. We attributed this to the shorter delivery path. A shorter delivery path also minimizes the risk of intracardiac 


\begin{tabular}{|c|c|c|c|}
\hline \multicolumn{3}{|l|}{ Study } & \multirow{2}{*}{$\begin{array}{l}\% \\
\text { Weight }\end{array}$} \\
\hline ID & & ES ( $85 \% \mathrm{Cl})$ & \\
\hline Changping Gan (2008) & - & $0.00(-0.01,0.01)$ & 12.92 \\
\hline Xiang-Jun Zeng (2008) & + & $0.00(-0.02,0.03)$ & 7.37 \\
\hline Xing Cuansheng (2008) & - & $0.00(-0.01,0.01)$ & 11.76 \\
\hline Kaiyu Tao (2010) & & $0.05(-0.01,0.10)$ & 2.48 \\
\hline Hua Cao (2011) & + & $0.00(-0.01,0.01)$ & 10.89 \\
\hline Da Zhu (2012) & +- & $0.08(-0.01,0.16)$ & 1.22 \\
\hline Qiang Chen (2012) & & $0.30(0.21,0.40)$ & 0.81 \\
\hline Gui-Can Zhang (2013) & $\rightarrow$ & $0.01(-0.01,0.04)$ & 6.34 \\
\hline Lin Liu (2013) & 1 & $0.08(-0.01,0.13)$ & 1.61 \\
\hline Shunmin Wang (2013) & - & $0.00(-0.00,0.00)$ & 13.54 \\
\hline Yu Kun Luo (2014) & $\rightarrow-$ & $0.08(0.02,0.09)$ & 4.78 \\
\hline Yijie Hu (2014) & - & $0.00(-0.00,0.01)$ & 13.09 \\
\hline Yong Sun (2018) & $\longrightarrow$ & $0.07(-0.01,0.15)$ & 1.27 \\
\hline Web-Gin Ou-yang (2017) & $\bullet$ & $0.07(0.05,0.09)$ & 8.20 \\
\hline Guan-Hua Fang (2018) & 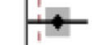 & $0.04(0.00,0.09)$ & 3.61 \\
\hline Overall (l-squared $=87.3 \%, p=0.000)$ & 0 & $0.02(0.01,0.03)$ & 100.00 \\
\hline NOTE: Weights are from random effects analysis & & & \\
\hline $\begin{array}{c}1 \\
-360 \\
-300\end{array}$ & 0 & 98 & \\
\hline
\end{tabular}

Fig. 6 Forest plot of total postoperative residual shunting rate

Table 2 The pooled rate of severe intra-operative, postoperative and follow-up complications

\begin{tabular}{|c|c|c|c|c|c|c|}
\hline Pooled events & Events(n) & $\%$ & Included studies & Incidence $(95 \% \mathrm{Cl})$ & Heterogeneity $\left(1^{2}\right)$ & $P$ \\
\hline Total severe complications & 109 & 100 & 15 & $0.074(0.046-0.102)$ & 78.00 & 0.00 \\
\hline Intra-operative & 88 & 80.73 & 15 & $0.050(0.028-0.071)$ & 71.00 & 0.00 \\
\hline significant residual shunt & 32 & 29.36 & 15 & $0.006(0.001-0.011)$ & 50.00 & 0.01 \\
\hline newly AR & 31 & 28.44 & 15 & $0.008(0.002-0.014)$ & 48.30 & 0.02 \\
\hline AVB & 10 & 9.17 & 15 & $0.003(0.000-0.005)$ & 0.00 & 0.94 \\
\hline failure in establishing track & 8 & 7.33 & 15 & $0.001(-0.001-0.003)$ & 0.00 & 0.90 \\
\hline newly TR & 7 & 6.42 & 15 & $0.001(-0.001-0.003)$ & 0.00 & 0.93 \\
\hline Postoperative & 12 & 11.01 & 15 & $0.000(-0.000-0.000)$ & 0.00 & 0.58 \\
\hline newly TR & 1 & 0.92 & 15 & $0.000(-0.000-0.000)$ & 0.00 & 1.00 \\
\hline newly AR & 0 & 0.00 & 15 & $0.000(-0.000-0.000)$ & 0.00 & 1.00 \\
\hline AVB & 5 & 4.59 & 15 & $0.000(-0.000-0.000)$ & 0.00 & 0.98 \\
\hline occluder dislogement & 2 & 1.83 & 15 & $0.000(-0.000-0.000)$ & 0.00 & 1.00 \\
\hline second operation & 4 & 3.67 & 15 & $0.000(-0.000-0.000)$ & 0.00 & 1.00 \\
\hline Follow-up period & 9 & 8.26 & 15 & $0.000(-0.000-0.000)$ & 0.00 & 0.49 \\
\hline AVB & 3 & 2.75 & 15 & $0.000(-0.000-0.000)$ & 0.00 & 0.99 \\
\hline$A R$ & 5 & 4.59 & 15 & $0.000(-0.000-0.000)$ & 0.00 & 0.98 \\
\hline TR & 0 & 0.00 & 15 & $0.000(-0.000-0.000)$ & 0.00 & 1.00 \\
\hline Reisidual shunt & 1 & 0.92 & 15 & $0.000(-0.000-0.000)$ & 26.90 & 0.18 \\
\hline
\end{tabular}

All residual shunt, AR, TR listed in this table were all above mild. AVB listed in this table included Mobitz type II atrioventricular block and complete AVB $T R$ tricuspid regurgitation, $A R$ aortic regurgitation, $A V B$ atrioventricular block 
structural damage due to catheter friction and rubbing. Thus, for experienced cardiac surgeons, the learning curve is short, and the promising prospects of this technology are easily promoted.

The pooled rate of postoperative residual shunting was 0.02 (95\% CI: $0.01-0.03, \mathrm{I}^{2}=87.3 \%, P=0.00$ ). However, most of the shunts disappeared during the follow-up period, and the pooled follow-up rate of residual shunting was 0.00 (95\% CI: $0.000-0.000, \mathrm{I}^{2}=30.5 \%, P=0.00$ ). Only 1 case of mild residual shunting during the follow-up period was observed. This change means that most residual shunts disappeared naturally during the follow-up period. Endothelialization finished several weeks after the operation, covering the surface of the device and forming neointima, thereby fully closing the residual shunt [30].

The pooled rate of severe intraoperative complications was 0.050 (95\% CI: $0.028-0.071, \mathrm{I}^{2}=71.0 \%, P=0.000$ ). Patients with severe intraoperative complications, including significant residual shunting, mild to significant aortic regurgitation, severe arrhythmia, failure to establish a path and mild to significant tricuspid regurgitation, were all converted to conventional surgical repair under $\mathrm{CPB}$. Significant residual shunting and mild to significant aortic regurgitation were the most common reasons for conversion. The incidence rates of severe arrhythmia, failure to establishing a path and mild to significant tricuspid regurgitation were low in perventricular device closure of pmVSD. $\mathrm{Hu}$ and his coworkers contributed approximately $10 \%$ of transthoracic device closure (TTDC) conversion to conventional surgical repair to unsuitable occluders, as all complications were resolved by removing the occluder [22]. A lack of multiple attempts with different types and sizes of occluders may also be a reason for conversion. Thus, among selected studies, the rate of conversion to surgical repair may also be identical. Upon the occurrence of complete atrioventricular block (cAVB), significant residual shunting $(>2$ $\mathrm{mm}$ ), new aortic regurgitation, or mild to significant tricuspid regurgitation, the procedure was converted to conventional surgical repair with $\mathrm{CPB}$. Most complications disappeared after removal of the occluder, suggesting the importance of choosing a suitable occluder type and size. Asymmetrical and symmetrical occluders were the most widely used occluders and were selected for TTE/ TTE-measured defect-to-aortic valve rims $<2 \mathrm{~mm}$ and $\geq$ $2 \mathrm{~mm}$. The occluder size was selected according to the pmVSD diameter and was larger than the pmVSD by $1-2$ $\mathrm{mm}$. Failure to establish a path was reported in 5 studies, with a pooled rate of 0.000 (95\% CI: $-0.000-0.000, \mathrm{I}^{2}=$ $0.0 \%, P=0.901$ ). The precondition of establishing a path is finding a suitable puncture site perpendicular to the plane of the VSD. Surgeons mostly determine the puncture site by depressing the right ventricular free wall with an index finger to find the strongest pulsatory site under continuous TEE/TTE guidance. Unsuitable puncture results in the failure to establish a path.

The pooled rate of severe postoperative complications was 0.000 (95\% CI: $0.000-0.000, \mathrm{I}^{2}=71.0 \%, P=0.000$ ). A total of 4 patients required a second operation, including 1 for occluder dislodgement and 3 for cAVB. Another patient with CAVB recovered a sinus rhythm and did not undergo a second operation or permanent pacemaker. Occluder dislodgement may be a procedure-related complication caused by a lack of experience with TTDC. In other cases of postoperative arrhythmia mentioned in the enrolled studies, a sinus rhythm was recovered within 48 $72 \mathrm{~h}$ after surgery. This finding may be attributable to early procedure-related inflammation or the limited number of cases [18]. Only one patient experienced new mild tricuspid regurgitation, which disappeared during the follow-up period. No cases of new mild or significant aortic regurgitation were observed. The pooled rates of aortic regurgitation and tricuspid regurgitation were both 0.000 (95\% CI: $0.000-0.000, \mathrm{I}^{2}=0.0 \%, P=1.0$ ). This promising result may be attributable to suitable occluder selection or the limited number of cases in this meta-analysis.

The pooled rate of severe complications in the followup period was 0.000 (95\% CI: $-0.000-0.000, \mathrm{I}^{2}=0.0 \%, P=$ 0.487 ), including 3 cases of late cAVB, 5 cases of mild aortic regurgitation, and 1 case of residual shunting $(>2 \mathrm{~mm})$. The above 3 patients with late CAVB recovered a sinus rhythm spontaneously or after steroid therapy. However, previous reports have emphasized that once late-onset cAVB occurs, a permanent pacemaker is the only cure for cAVB, which is in contrast to the above findings [31, 32]. One possible explanation may be that the conduction system was recently affected by the device-related inflammatory response or scar formation and the patients came to hospital for therapy immediately.

The mechanism of cAVB remains unclear. It is possible that occluder devices may cause an initial inflammatory response with subsequent formation and fibrosis in the conduction system [14]. Progressive device flattening may also be a mechanism for the development of cAVB, according to Butera G's hypothesis [33]. Compared with the transcatheter approach, perventricular device closure involves a shorter path and thus avoids friction and rubbing of the conduction system and the subsequent inflammation. Meta-regression analysis indicated no significant correlation between early/late $\mathrm{CAVB}$ and the following factors: publication year, sample size, study type, mean age, mean VSD size, male prevalence, occluder-VSD size difference and TTE/TEE guidance (all $P>0.05$ ). It is still a challenge to completely avoid cAVB given the surrounding anatomical structures in pmVSD; thus, precautions with suitable device selection (both type and size) are paramount. Certain devices have already been approved in some countries for use in pmVSD closure. No one type of 
occluder is suitable in all cases of VSD; thus, progressive improvements of these devices are also necessary.

Aortic regurgitation is another severe complication of perventricular device closure due to the short subaortic rim of pmVSD and the use of unsuitable occluders. Only 5 cases of mild aortic regurgitation were observed during the follow-up period. The pooled rate of aortic regurgitation in the follow-up period was 0.000 (95\% CI: - 0.000$0.000, \mathrm{I}^{2}=0.0 \%, P=0.982$ ). This result show that the incidence of aortic regurgitation in the follow-up period was low, emphasizing the importance of accurately evaluating the subaortic rim and choosing a suitable occluder.

\section{Conclusion}

Perventricular device closure may be an alternative to conventional surgical repair in selected patients with pmVSD. This meta-analysis proves perventricular device closure of pmVSD to be safe and effective. The success rate was stable regarding the publication year and sample size and suggested the short learning curve of this technology and its prospects for wide application. The incidence of severe arrhythmia, especially cAVB, was low. These good results may be limited by the number of enrolled patients, and more detailed observations in a larger sample are required for further analysis.

\section{Study limitations}

First, heterogeneity existed in this meta-analysis, largely due to differences in study design. Second, several studies enrolled in the meta-analysis did not provide sufficient information regarding major outcomes. Some studies reported all cases of arrhythmia, whether severe or minor, while others only reported cases of severe arrhythmia. Difficulties were encountered when classifying complications into transient and permanent subgroups, as most studies included patients who did not receive or report all of the appropriate follow-up endpoints. The follow-up period was different in each study. It is difficult to define transient or permanent; we only enrolled cases reported at the final follow-up review as being permanent and recorded all other cases as being transient. Most studies did not provide subarterial rim data or the type of occluder used in patients. Third, this analysis included case series and case-control studies but no randomized controlled studies. Finally, there was acceptable publication bias in this study.

\section{Abbreviations}

AR: Aortic regurgitation; AVB: Atrioventricular block; CAVB: Complete atrioventricular block; CPB: Cardiopulmonary bypass; NOS: Newcastle-Ottawa Scale; pmVSD: Perimembranous ventricular septal defects; TEE: Transesophageal echocardiography; TR: Tricuspid regurgitation; TTDC: Transthoracic device closure; TTE: Transthoracic echocardiography
Ethical approval and consent to participate

The present study was approved by the ethics committee of Fujian Medical University, China and adhered to the tenets of the Declaration of Helsinki.

\section{Authors' contributions}

$\mathrm{HC}$ designed the study and submitted the manuscript. Z-NH, QC, L-QH collected and analyzed data together. Z-NH drafted the article. All authors read the final version of this article and approved for publication.

\section{Funding}

Not applicable.

\section{Availability of data and materials}

Data sharing not applicable to this article as no data sets were generated or analyzed during the current study.

Consent for publication

Not applicable.

\section{Competing interests}

The authors declare that they have no competing interests.

\section{Author details}

${ }^{1}$ Department of Cardiac Surgery, Fujian Provincial Maternity and Children's Hospital, Affiliated Hospital of Fujian Medical University, Fuzhou 350001, People's Republic of China. ${ }^{2}$ Department of Cardiovascular Surgery, Union Hospital, Fujian Medical University, Fuzhou 350001, People's Republic of China. ${ }^{3}$ Department of Public Health, Fujian Medical University, Fuzhou 350001, People's Republic of China.

Received: 9 May 2019 Accepted: 17 June 2019

Published online: 27 June 2019

References

1. Anderson $\mathrm{RH}$, Becker $\mathrm{AE}$, Tynan M. Description of ventricular septal defects_or how long is a piece of string? Int J Cardiol. 1986;13(3):267-78.

2. Soto B, Becker AE, Moulaert AJ, Lie JT, Anderson RH. Classification of ventricular septal defects. Br Heart J. 1980;43(3):332-43.

3. Hazekamp MG, Gomez AA, Koolbergen DR, Hraska V, Metras DR, Mattila IP, Daenen W, Berggren HE, Rubay JE, Stellin G. Surgery for transposition of the great arteries, ventricular septal defect and left ventricular outfow tract obstruction: European congenital heart surgeons association multicentre study. Eur J Cardiothorac Surg. 2010;38:699-706.

4. Roos-Hesselink JW, Meijboom FJ, Spitaels SE, Van Domburg R, Van Rijen EH, et al. Outcome of patients after surgical closure of ventricular septal defect at young age: longitudinal follow-up of 22-34 years. Eur Heart J. 2004;25(12):1057-62.

5. Li-Jian Z, Bo H, Jian-Jun Z, Yi Y-C, Dian-Dong J, Jian-Li L. Postprocedural outcomes and risk factors for arrhythmias following Transcatheter closure of congenital Perimembranous ventricular septal defect: a single-center retrospective study [J]. Chin Med J. 2017;130(5):516-21.

6. Schipper M, Slieker MG, Schoof PH, Breur JM. Surgical repair of ventricular septal defect, contemporary results and risk factors for a complicated course. Pediatr Cardiol. 2017;38(2):264-70.

7. Heiberg J, Ringgaard S, Schmidt MR, Redington A, Hjortdal VE. Structural and functional alterations of the right ventricle are common in adults operated for ventricular septal defect as toddlers. Eur Heart J Cardiovasc Imaging. 2015;16(5):483-9.

8. Zhao LJ, Han B, Zhang JJ, Yi YC, Jiang DD, et al. Postprocedural outcomes and risk factors for arrhythmias following Transcatheter closure of congenital Perimembranous ventricular septal defect: a single-center retrospective study. Chin Med J. 2017;130(5):516-21.

9. Yang L, Tai BC, Khin LW, Quek SC. A systematic review on the efficacy and safety of transcatheter device closure ofventricular septal defects (VSD). J Interv Cardiol. 2014;27(3):260-72.

10. Chungsomprasong P, Durongpisitkul K, Vijarnsorn C, Soongswang J, Lê TP. The results of transcatheter closure of VSD using Amplatzer ${ }^{\circledast}$ device and nit Occlud $^{\circledast}$ Lê coil. Catheter Cardiovasc Interv. 2011;78(7):1032-40.

11. Gan C, An Q, Lin K, Tang H, Lui RC, Tao K, Pan W, Shi Y. Perventricular device closure of ventricular septal defects: six months results in 30 young children. Ann Thorac Surg. 2008;86(1):142-6. 
12. Zeng XJ, Sun SQ, Chen XF, Ma XJ, Luo YH, Lim YP, Tao L. Device closure of perimembranous ventricular septal defects with a minimally invasive technique in 12 patients. Ann Thorac Surg. 2008;85(1):192-4.

13. Quansheng X, Silin P, Zhongyun Z, Youbao R, Shengde L, Qian C, Shuhua D, Kefeng $H$, Zhixian J, Qin W. Minimally invasive perventricular device closure of an isolated perimembranous ventricular septal defect with a newly designed delivery system: preliminary experience. J Thorac Cardiovasc Surg. 2009:137(3):556-9.

14. Tao K, Lin K, Shi Y, Song H, Lui RC, Gan C, An Q. Perventricular device closure of perimembranous ventricular septal defects in 61 young children: early and midterm follow-up results. J Thorac Cardiovasc Surg. 2010 Oct: 140(4):864-70.

15. Cao H, Chen Q, Zhang G-C, Chen L-W, Li Q-Z, Qiu Z-H. Intraoperative device closure of perimembranous ventricular septal defects in the young children under transthoracic echocardiographic guidance, initial experience. J Cardiothorac Surg. 2011;6:166.

16. Zhu D, Gan C, Li X, An Q, Luo S, Tang H, Feng Y, Lin K. Perventricular device closure of perimembranous ventricular septal defect in pediatric patients: technical and morphological considerations. Thorac Cardiovasc Surg. 2013 Jun;61(4):300-6.

17. Chen Q, Cao H, Zhang GC, Chen LW, Li QZ, Qiu ZH. Closure of perimembranous ventricular septal defects with intraoperative device technique: another safe alternative to surgical repair. Thorac Cardiovasc Surg. 2013 Jun;61(4):293-9.

18. Zhang GC, Chen Q, Cao H, Chen LW, Yang LP, Chen DZ. Minimally invasive perventricular device closure of ventricular septal defect in infants under transthoracic echocardiograhic guidance: feasibility and comparison with transesophageal echocardiography. Cardiovasc Ultrasound. 2013;11:8.

19. Liu L, Zhao TL, Yang YF, Wang X, Ying N, Wu Q, Gao N. Intraoperative device closure of subaortic ventricular septal defects. J Card Surg. 2013; 28(4):456-60.

20. Wang S, Zhuang Z, Zhang H, Zhen J, Lu Y, Liu J, Xu Z. Perventricular closure of perimembranous ventricular septal defects using the concentric occluder device. Pediatr Cardiol. 2014;35:580.

21. Luo YK, Chen WH, Xiong C, Li CC, Chen LL. Comparison of effectiveness and cost between perventricular device occlusion and minimally invasive surgical repair for perimembranous ventricular septal defect. Pediatr Cardiol. 2015;36(2):308-13.

22. Hu Y, Li Z, Chen J, Li F, Shen C, Song Y, Zhao S, Peng C, Chen M, Zhong Q. Results of comparing transthoracic device closure and surgical repair with right infra-axillary thoracotomy for perimembranous ventricular septal defects. Interact Cardiovasc Thorac Surg. 2015;20(4):493-8.

23. Sun Y, Zhu P, Zhou P, Guo Y, Zheng SY. Intra-operative device closure of perimembranous ventricular septal defect without cardiopulmonary bypass under guidance of trans-epicardial echocardiography: a single center experience. J Cardiothorac Surg. 2016;11:87.

24. Ou-Yang WB, Wang SZ, Hu SS, Zhang FW, Zhang DW, Liu Y, Meng H, Pang KJ, Meng LK, Pan XB. Perventricular device closure of perimembranous ventricular septal defect: effectiveness of symmetric and asymmetric occluders. Eur J Cardiothorac Surg. 2017;51(3):478-82.

25. Fang GH, Chen Q, Hong ZN, Lin ZW, Zhang GC, Cao H, Chen LW. The comparison of Perventricular device closure with Transcatheter device closure and the surgical repair via median sternotomy for Perimembranous ventricular septal defect. Ann Thorac Cardiovasc Surg. 2018;24(6):308-14.

26. Stang A. Critical evaluation of the Newcastle-Ottawa scale for the assessment of the quality of nonrandomized studies in meta-analyses. Eur J Epidemiol. 2010;25:603-5.

27. Deeks JJ, Dinnes J, D'Amico R, Sowden AJ, Sakarovitch C, Song F, Petticrew M, Altman DG, International Stroke Trial Collaborative Group; European Carotid Surgery Trial Collaborative Group. Evaluating non-randomised intervention studies. Health Technol Assess. 2003;7(27):1-173 iii-X.

28. Amin Z, Berry JM, Foker JE, Rocchini AP, Bass JL. Intraoperative closure of muscular ventricular septal defect in a canine model and application of the technique in a baby. J Thorac Cardiovasc Surg. 1998;115:1374-6.

29. Amin Z, Danford DA, Lof J, Duncan KF, Froemming S. Intraoperative device closure of perimembranous ventricular septal defects without cardiopulmonary bypass: preliminary results with the perventricular technique. J Thorac Cardiovasc Surg. 2004;127(1):234-41.

30. Chen Q, Hong ZN, Zhang GC, Chen LW, Zhang QL, Lin ZW, Cao H. Intraoperative device closure of isolated ventricular septal defects: experience on 1,090 cases. Ann Thorac Surg. 2018;105(6):1797-802.
31. Carminati M, Butera G, Chessa M, De Giovanni J, Fisher G, et al. Investigators of the European VSD registry. Transcatheter closure of congenital ventricular septal defects: results of the European registry. Eur Heart J. 2007; 28(19):2361-8.

32. Zhou K, Hua Y, Qiao L. A case of late-onset sustained ventricular tachycardia following deployment of Amplatzer-type perimembra-nous VSD occluder. Catheter Cardiovasc Interv. 2014;83(2):256-60.

33. Butera G, Massimo C, Mario C. Late complete atriovenous block after percutaneous closure of a perimembranous ventricular septal defect. Catheter Cardiovasc Interv. 2006;67(6):938-41.

\section{Publisher's Note}

Springer Nature remains neutral with regard to jurisdictional claims in published maps and institutional affiliations.
Ready to submit your research? Choose BMC and benefit from:

- fast, convenient online submission

- thorough peer review by experienced researchers in your field

- rapid publication on acceptance

- support for research data, including large and complex data types

- gold Open Access which fosters wider collaboration and increased citations

- maximum visibility for your research: over $100 \mathrm{M}$ website views per year

At BMC, research is always in progress.

Learn more biomedcentral.com/submissions 